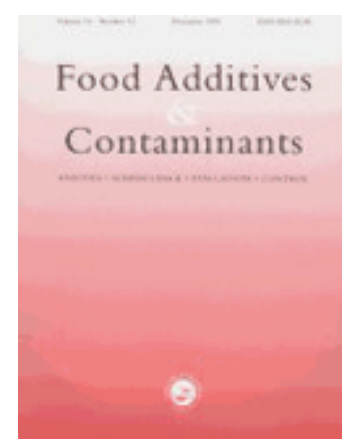

\title{
Concentrations of undeclared allergens in food products can reach levels that are relevant for public health
}

\begin{tabular}{|r|l|}
\hline Journal: & Food Additives and Contaminants \\
\hline Manuscript ID: & TFAC-2009-172.R1 \\
\hline Manuscript Type: & Original Research Paper \\
\hline Author: & 18-Aug-2009 \\
\hline Complete List of Authors: & $\begin{array}{l}\text { Spanjersberg, Marielle; TNO, Food and Chemical Risk Analysis } \\
\text { Knulst, André; University Medical Center, Dermatology and } \\
\text { Allergology } \\
\text { Kruizinga, Astrid; TNO, Food and Chemical Risk Analysis } \\
\text { Van Duijn, Gert; TNO, Analytical Research } \\
\text { Houben, Geert; TNO, Food and Chemical Risk Analysis }\end{array}$ \\
\hline Methods/Techniques: & $\begin{array}{l}\text { Probabalistic modelling, Risk assessment, Risk assessment - } \\
\text { modelling }\end{array}$ \\
\hline Additives/Contaminants: & Allergens \\
\hline Food Types: & Cocoa, Processed foods \\
\hline & \\
\hline
\end{tabular}

\section{SCHOLARONE ${ }^{\text {M }}$ Manuscripts}


Risk Undeclared Allergens

\title{
Concentrations of undeclared allergens in food products can reach levels that are relevant for public health
}

\author{
Spanjersberg MQI ${ }^{1}$, Knulst AC ${ }^{2}$, Kruizinga $\mathrm{AG}^{1}$, Van Duijn $\mathrm{G}^{3}$, Houben $\mathrm{GF}^{1}$ \\ ${ }^{1}$ TNO Quality of Life, Department Food and Chemical Risk Analysis, Zeist, The Netherlands \\ ${ }^{2}$ University Medical Center, Department of Dermatology and Allergology, Utrecht, The \\ Netherlands \\ ${ }^{3}$ TNO Quality of Life, Department Analytical Research, Zeist, The Netherlands
}

\begin{abstract}
Food products can become contaminated with food allergens due to cross contact. Precautionary 'may contain' labelling may alert to the possible presence of an allergen but guidance for such labeling is lacking. As a result, allergy information on the packaging may not be reliable and allergic consumers may be at risk of allergic reactions after consuming unlabelled but indeed contaminated products. Recently, a cow's milk protein allergic patient experienced a severe allergic reaction to a dark chocolate product containing undeclared milk proteins. This case induced us to investigate to what extent allergen concentrations of unlabelled products reach levels that are of public health relevance. The concentrations of milk proteins in the complaint sample and a collection of products of other batches and brands purchased from different stores were analysed. Together with appropriate threshold and food consumption data, the risks of allergic reactions and the severity of these reactions within the adult milk allergic population were determined by using probabilistic risk assessment techniques. The results show that milk protein concentrations in unlabelled products reach levels that may elicit allergic reactions in up to $68 \%$ of the adult allergic consumers. Concentrations of allergens in unlabelled products could reach levels that are of public health relevance. Application of probabilistic risk assessment can be an aid in revealing the public health consequences of undeclared allergens in food, in risk management decision making and developing guidance in terms of risk-based concentration limits for precautionary labelling.
\end{abstract}


Risk Undeclared Allergens

Keywords: Allergen contamination; Food Allergy; Risk Assessment; Probabilistic; May Contain Labelling; Milk Protein; Dark Chocolate; Risk-Based Concentration Limits

\section{Introduction}

As only strict avoidance of food allergens can prevent an allergic reaction, the allergic consumer relies on the allergy information on the packaging. Declaration of certain allergenic ingredients is obligatory and clearly defined in directives (2003/89/EC and 2005/26/EC). An allergen can also be present due to cross contact, for instance if a production line cannot be cleaned completely after producing an allergen containing product or due to cross contact in the raw material or ingredient supply chains. In such cases, precautionary 'may contain' labelling may alert to the possible presence of the concerned allergen. However, there is no guidance for the use of 'may contain' labeling in most countries. In the absence of such guidance, many producers seem to choose to label products precautionary in case they cannot guarantee full absence of allergens, even if the chance of contamination and/or the potential health impact are negligible. This leads to unnecessary limitation of consumer choice and devaluation of the allergen labelling information (Health Council of the Netherlands (GR) 2007). On the other hand, many products fill the shelves that appear to contain allergens while there is no warning on the labels, as shown by two recent surveys. The Dutch Food and Consumer Product Safety Authority performed a survey in order to make an inventory of the percentage of products either labelled or not to (possibly) contain allergen. Several types of products were analysed for traces of certain allergens. In $32 \%$ of 44 products not labelled for peanut, the allergen was detectable at different concentrations. Casein was detected in $45 \%$ of 64 products not labelled for milk proteins (VWA 2007). Comparable results were obtained in a survey by Pele et al. Hundreds of different types of cookies and chocolates were purchased in different countries in Europe and analysed for peanut and hazelnut proteins. Cookies not declared to (possibly) contain peanut or hazelnut proteins were analysed positive for these proteins in $11 \%$ and $25 \%$ of the samples, respectively. For chocolates, these percentages were $25 \%$ and $53 \%$ (Pele et al 2007).

Both situations - unlabelled contaminated products and labelled products with negligible contamination chance - are undesirable. Only in situations where cross contact is likely and health risks are expected, 'may contain' labelling should be adopted. It is, however, difficult to assess when such a situation applies. 
Risk Undeclared Allergens

We previously developed a risk assessment methodology that calculates the magnitude of a potential public health risk posed by defined concentrations of food allergens. Probabilistic modelling of adequate food consumption, allergen concentration and threshold distributions can establish what proportion of the at-risk population could be expected to react, subdivided into the severity of the reaction (Spanjersberg et al 2007, Kruizinga et al 2008).

By now, probabilistic modelling is considered to be the most promising approach for use in population risk assessment (Madsen et al 2008) and can be used for establishing risk-based concentration limits for 'may contain' labelling as well.

Recently, a cow's milk protein allergic patient from the outpatient department of the University Medical Centre Utrecht, The Netherlands, experienced a severe allergic reaction to a dark chocolate product that was not declared to contain milk. This case induced us to investigate to what extent allergen concentrations of unlabelled products reach levels that are of public health relevance.

\section{Case description}

A 38 year-old female patient, with adult onset cow's milk and hen's egg allergy since her early twenties, followed a strict elimination diet. In 1998 she suffered a severe allergic reaction to a sandwich with salmon due to the hidden presence of casein in the salmon (Koppelman et al 1999). Recently she visited the outpatient department of the University Medical Center (UMC) in Utrecht, The Netherlands, because she experienced an unexpected allergic reaction to dark chocolate sprinkles (a favourite sandwich filling in the Netherlands). Previously she experienced mild tingling in the mouth on several occasions after consuming one sandwich with the chocolate sprinkles, which she did not attribute to the product. Then after consumption of several slices of (milk-free) bread with this product on the same eating occasion, she had a more severe reaction. Within 30 minutes she got tingling lips, redness of the face, swelling of the eyes, sneezing and obstruction of the nose, nausea and itching in the inguinal area. She interpreted this correctly as a systemic allergic reaction, treated herself with oral antihistamines and went to a nearby physician who treated her with intravenous antihistamines. Subsequently the symptoms gradually disappeared. The patient read labels carefully and avoided products labelled to (possibly) contain milk proteins. The product in question was not declared to (possibly) contain milk proteins. 
Risk Undeclared Allergens

The complaint sample was brought along by the patient and was analysed for the presence of cow's milk and hen's egg proteins in order to find out the cause of her allergic reaction. Egg protein was shown to be absent, milk protein was indeed present (see sections below).

\section{Materials and methods}

In order to investigate to what extent products not declared to (possibly) contain certain allergens may contain these allergens at concentration levels that pose a risk to allergic consumers, we conducted a probabilistic risk assessment for a collection of the dark chocolate product type the patient reacted to.

The following data had to be collected: the distribution of the concentration of milk proteins in dark chocolate sprinkles, the consumption figures of dark chocolate sprinkles and the distributions of the eliciting doses (thresholds) for milk protein among milk protein allergic individuals.

\section{The concentration of milk protein in the dark chocolate product}

Twelve packages of nine different brands of dark chocolate sprinkles from different regional stores were collected. Samples of these packages as well as of the complaint sample were analysed. Three of these packages (from two brands) were labelled precautionarily for the possible presence of milk proteins; the other ten were not labelled. For comparison, three samples of milk chocolate sprinkles were analysed.

Milk protein predominantly consists of casein and $\beta$-lactoglobulin (approximately $85 \%$ and $10 \%$, respectively). Both of these protein groups were analysed in extracts of the samples. Because the patient from the case description also was allergic for hen's egg protein, egg proteins were determined as well. The chocolate sprinkles were processed to prepare extracts as follows. To $1 \mathrm{~g}$ of chocolate sprinkle sample $10 \mathrm{~mL}$ extraction buffer $(0.05 \mathrm{M}$ sodium carbonate, $\mathrm{pH}$ 9.6) was added. Since the presence of cocoa in a sample may inhibit the detection of milk proteins, the extraction procedure has been improved by the addition fish gelatin (Sigma G7765) to the extraction solution (10\% w/w) prior to the sample extraction as well as heating the mixture to $50-60{ }^{\circ} \mathrm{C}$ during extraction (according to the instructions of Tepnel). Commercially available ELISA kits were used to determine the concentrations of casein (Tepnel 902062W), $\beta$-lactoglobulin (Tepnel 902060Y) and egg protein (Tepnel 902072T). The procedure was performed according to the directions of use included by 
Risk Undeclared Allergens

Tepnel and measured with a Spectramax. The limits of detection were $1 \mathrm{mg} / \mathrm{kg}$. The analyses were performed in triplicate.

The concentrations of milk proteins determined for the ten unlabelled products were used for risk assessment.

\section{The consumption of dark chocolate sprinkles}

The consumption of dark chocolate sprinkles is represented by two variables: the probability of using dark chocolate sprinkles and the amount of sprinkles consumed. Consumption data were derived from the Netherlands Food Consumption Survey from 2003, in which a representative sample of 352 male and 398 female consumers aged 19-30 years recorded their food consumption for two non-consecutive days (Hulshof et al 2004). In the absence of specific food consumption data from allergic consumers, we assumed that the pattern of consumption does not differ between allergic consumers and the general population. The chance of consumption was based on the number of people who consumed the product on measurement day 1 and/or day 2; the amount consumed was based on the highest individual amount consumed on day 1 or 2 . Because the consumption pattern differs between males and females, we separated the consumption part of the assessment and calculated their risk separately. The proportion of the population consuming the product and the amounts consumed were established to be $12.5 \%$ and $16.1 \pm 8.9 \mathrm{~g}$ and $10.1 \%$ and $10.7 \pm 8.2 \mathrm{~g}$ for males and females, respectively.

\section{The minimum eliciting doses (thresholds) of milk protein in milk protein allergic adults}

Data on minimum eliciting doses of cow's milk protein in cow's milk allergic patients can be derived from several publications. However, most of these provocation studies have been performed in children. Thresholds established in children may not be comparable to those of adults. As we intended to conduct a risk assessment for the adult allergic population, we used the results of a recent provocation study in adult patients in which minimum eliciting doses were established with double-blind placebo-controlled food challenges (DBPCFC). Ten patients with clinically established cow's milk protein allergy were challenged with increasing doses of milk protein in order to determine the minimum eliciting doses for both subjective and objective symptoms (for study details and results see Lam et al 2008).

Subjective symptoms (for instance itch, nausea, abdominal pain and dizziness) can only be reported by the subject being challenged and are thought to be the preliminary stages of the 
Risk Undeclared Allergens

subsequent objective reactions (in this instance urticaria, vomiting, diarrhoea and drop in blood pressure), which can be verified independently by an outside observer. In an individual patient, subjective effects usually occur at lower challenge doses than those eliciting objective symptoms. In our case study we used minimum eliciting dose distributions for both subjective and objective reactions to assess the probability for different types of reactions separately.

\section{Probabilistic modelling}

The data distributions of consumption and concentration were defined as cumulative distributions. Threshold data can be fitted as Cumulative, LogLogistic, LogNormal or Weibull distributions. As there is no apparent biological or mathematical basis for choosing one of these statistical distributions, we calculated the results for all four distributions. The parameters of the chosen distributions were defined using SAS (version 9.1) and entered in the software programme @-RISK, with 25 runs of 10000 iterations for each simulation, a procedure reported in detail in a previous publication (Spanjersberg et al 2007).

\section{Results}

\section{Milk and egg protein concentrations}

Casein and $\beta$-lactoglobulin analysis showed similar patterns. As casein is the predominant milk protein and can thus be measured more accurately, concentrations of total milk protein were calculated from the casein results. The results of the analysis and calculation of the casein and total milk protein concentrations in chocolate sprinkles are summarized in table 1. Egg protein was found to be absent in all samples $(<1 \mathrm{mg} / \mathrm{kg})$.

$<$ INSERT Table $1 \mathrm{a}$ and $1 \mathrm{~b}$ and $1 \mathrm{c}>$

\section{Probabilistic risk assessment}

The results of the risk assessment were expressed as the percentages of the milk protein allergic adult male or female population expected to experience an allergic reaction due to dark chocolate sprinkles not labelled to (possibly) contain milk proteins. The results are shown in figure 1 and table 2. The threshold data were fitted in different statistical distributions each resulting in a calculated risk. The worst-case outcomes are reported in this publication. 
Risk Undeclared Allergens

Standard deviations were too low to have impact on the outcome and are therefore not reported. After all, for risk management of population risks, a calculated risk of for instance $15 \%$ is not expected to differ fundamentally from $14 \%$ or $16 \%$ in terms of indicated risk management measures.

For objective symptoms, a cumulative threshold distribution underestimates the risk, because the model assumes that below the lowest eliciting dose for objective reactions observed in the provocation study no reaction can occur. In reality, below this dose reactions do occur, yet these are often subjective and therefore not included in the distribution for objective effects. Therefore, a cumulative distribution was not included in the calculation of the percentage of the allergic population expected to respond objectively.

$<$ INSERT Table 2>

$<$ INSERT Figure 1>

Table 2 shows that a large percentage of milk allergic subjects would react if they ate the product. The sample the patient brought along (complaint sample: brand 1 production code a) was calculated to pose a risk of subjective complaints in $57.5 \%$ and $50.3 \%$ of the milk allergic male and female consumers of dark chocolate sprinkles, respectively. The expected risk for objective allergic reactions was calculated to be $7.7 \%$ and $5.8 \%$ of the milk allergic consumers (males and females, respectively).

The sample with the highest contamination level (brand 1 production code $\mathrm{c}$ ) is expected to cause subjective allergic reactions in $67.9 \%$ and $61.3 \%$ and objective allergic reactions in $12.2 \%$ and $9.2 \%$ of the milk allergic consumers (males and females, respectively).

Because not all milk allergic individuals will consume dark chocolate, the risk calculated for the milk allergic population is lower. If non-users of dark chocolate sprinkles are included, the percentage of responders to the complaint sample, for instance, was calculated to be 5.0-7.2\% for subjective allergic reactions and $0.6-1.0 \%$ for objective symptoms.

The four statistical distributions (Cumulative, LogLogistic, LogNormal and Weibull) in which the thresholds for subjective symptoms were fitted resulted in similar outcomes. For objective symptoms the chosen distribution was found to have consequences for the outcome, as reflected in a broader outcome range. 
Risk Undeclared Allergens

\section{Discussion}

The decision whether or not a potentially contaminated product should be labelled precautionarily is often difficult to make. Labelling of a product contributes to the protection of allergy patients, but, in case of a negligible risk, leads to unnecessary limitation of consumer's food choice and devaluation of the allergen information value on the packaging. Not labelling, on the other hand, results in an inability for allergic subjects to avoid a potentially contaminated product and would pose a risk to the allergic consumer in case the allergen is present at a quantity that provokes a reaction. The patient case described and analytical results demonstrate that this latter situation indeed occurs. The patient read labels carefully and avoided products labelled to (possibly) contain milk proteins, but was not warned for the possible presence of milk proteins in the product she consumed.

It is not known to what extent allergic consumers suffer from allergic reactions caused by hidden allergens in food. The results from our study suggest that it might be expected to occur rather frequently. In practice, however, complaints about products are not known to be reported frequently. On the basis of our patient case, it can be postulated that the problem may be underreported, as allergic consumers may often be unable to link complaints to a consumed food or just do not seek medical attention because the response is mild and transitory. Our patient experienced mild tingling in the mouth at several occasions after consuming one sandwich with the chocolate sprinkles, which she did not attribute to the product. Only after consumption of several slices of bread with the product on one eating occasion, she had a more severe reaction and linked it to the sprinkles.

As mentioned before, results of two recent surveys (VWA 2007 and Pele et al 2007) indicate a poor reliability of allergy information on products as well. Thus, the presence of unlabelled allergens in foods may be considered as a real health problem.

In our study only a restricted amount of dark chocolate sprinkle samples was assessed as we aimed to investigate to what extent unlabelled products may be contaminated at levels that pose a risk to the allergic consumers and did not aim to perform a complete risk assessment of chocolate sprinkles. For population risk assessment purposes, more samples and aspects such as the prevalence of cow's milk protein allergy, protein levels in products of other brands and batches and the market share of the various brands would be required. 
Risk Undeclared Allergens

The representativeness of the threshold data distributions for milk protein may be discussed, as the number of participants was rather low. This dataset may be improved by including data of additional patients from other studies. An interval-Censoring Survival Analysis (ICSA) may be applied to pool the data from the available studies, as has been done with peanut threshold data by Taylor et al (2009). As many threshold data are available for children, inclusion of these data may strengthen this part of the risk assessment. In addition, keeping a separate data set for children, who generally have milder allergic reactions to milk protein, makes an assessment of their level of risk possible.

In a clinical setting, thresholds may differ from the real life situation. However, this is only speculative. In addition, it is important to realize that the applied risk assessment method uses human data of high quality and does not need any species to species extrapolation which generally is a most uncertain step in risk assessment for chemical substances.

A critical point of our study is the representativeness of the consumption data. Due to lack of consumption data within the allergic part of the population, we had to use consumption data of the general population, which may differ.

Despite the inadequateness of the available consumption data, the applied probabilistic risk assessment model is generally considered to be the most sophisticated approach.

The choices made with regard to the defined statistical models were shown to have little impact on the results. The four statistical distributions in which the thresholds for subjective symptoms were fitted resulted in similar outcomes. This shows that this risk assessment methodology is relatively insensitive to the type of statistical distribution chosen for the threshold data for subjective symptoms. The chosen distribution for objective symptoms had somewhat more impact. Mathematically the reason is obvious: the distribution for objective symptoms needs extrapolation towards the lower dose area (this distribution has no data points in the lower dose area, as most patients show subjective symptoms first) and uncertainty simply increases with the extent of low-dose extrapolation.

\section{Conclusion}

This study was conducted in order to investigate to what extent allergen concentrations in unlabelled products are relevant for public health. Milk protein concentrations in unlabelled dark chocolate sprinkles, probably present as a result of cross-contact, were shown to reach 
Risk Undeclared Allergens

levels that can cause serious allergic reactions within the milk allergic population, as evidenced by the patient case as described. Obviously, precautionary labelling needs guidance in terms of concentration levels that indicate when a product should be labeled precautionarily in order to be valuable to the consumer. Probabilistic allergen risk assessment can be an aid to establish risk-based concentration limits and can validate already existing limits. Now and in the future, probabilistic allergen risk assessment is a way to calculate the health risk impact of contaminated products and provides a sound basis for risk management decisions.

\section{Acknowledgement}

The authors would like to thank Frans van der Kloet, Carina Rubingh, Linda van den Bosch and Karin Hulshof for their statistical support and their contribution to the automation of the probabilistic calculation process in allergen risk assessment.

\section{References}

-Dutch Food and Consumer Product Safety Authority (Voedsel en Waren Autoriteit, VWA). Onderzoek naar de declaratie van allergenen op levensmiddelen. July 2007 [Report in Dutch]

-Health Council of the Netherlands (Gezondheidsraad, GR). Voedselallergie. Report No 2007/07 March 2007 [Report in Dutch]

-Hulshof KFAM, Ocké MC, Van Rossum CTM, Buurma-Rethans EJM, Brants HAM, Drijvers JJMM, Ter Doest D. Results of the Food Consumption Survey 2003. RIVM report 35003000/2004, TNO report V6000, 2004 [Report in Dutch]

-Koppelman SJ, Wensing M, De Jong GA, Knulst AC. Anaphylaxis caused by the unexpected presence of casein in salmon. Lancet 1999; 354(9196):2136

-Kruizinga AG, Briggs D, Crevel A, Knulst A, Van den Bosch L, Houben GF. Probabilistic risk assessment model for allergens in food: sensitivity analysis of the minimum eliciting dose and food consumption. Food and Chemical Toxicology 2008; 46: 1437-1443 
Risk Undeclared Allergens

-Lam HY, Van Hoffen E, Michelsen A, Guikers K, Van der Tas CHW, Bruijnzeel-Koomen CAFM, Knulst AC. Cow's milk allergy in adults is rare but severe: both casein and whey proteins are involved. Clinical and Experimental Allergy 2008; 38: 995-1002

-Madsen CB, Hattersley S, Buck J, Gendel SM, Houben GF, Hourihane JOB, Mackie A, Mills ENC, Nørhede P, Taylor SL, Crevel RWR. Approaches to Risk Assessment in Food Allergy: Report from a Workshop "Developing a framework for assessing the risk from allergenic foods". Food and Chemical Toxicology 2009; 47(2): 480-489

-Pele M, Brohée M, Anklam E, Van Hengel AJ. Peanut and hazelnut traces in cookies and chocolates: relationship between analytical results and declaration of food allergens on product labels. Food Additives and Contaminants 2007 24(12): 1334-1344

-Spanjersberg MQI, Kruizinga AG, Rennen MAJ, Houben GF. Risk assessment and food allergy: the probabilistic model applied to allergens. Food and Chemical Toxicology 2007; 45(1): $49-54$

-Taylor SL, Crevel RWR, Sheffield D, Kabourek J, Baumert J. Threshold dose for peanut: risk characterization based upon published results from challenges of peanut-allergic individuals. Food and Chemical Toxicology 47(6): 1198-1204 


\section{Risk Undeclared Allergens}

Table $1 a$

Concentrations of casein and total milk protein in dark chocolate sprinkles not labeled precautionarily for the presence of milk protein

\begin{tabular}{|l|l|l|}
\hline $\begin{array}{l}\text { Dark chocolate sprinkles } \\
\text { - not labeled for milk allergens - }\end{array}$ & $\begin{array}{l}\text { Casein concentration } \\
(\mathrm{mg} / \mathrm{kg})\end{array}$ & $\begin{array}{l}\text { Total milk protein } \\
\text { concentration* } \\
(\mathrm{mg} / \mathrm{kg})\end{array}$ \\
\hline $\begin{array}{l}\text { Brand 1 (production code a) ** } \\
\text { Brand 1 (production code b) }\end{array}$ & 1500 & 1765 \\
Brand 1 (production code c) & 85 & 100 \\
Brand 2 (production code a) & 4015 & 3547 \\
Brand 2 (production code b) & 1568 & 540 \\
Brand 3 & 15 & 1845 \\
Brand 4 & 2 & 18 \\
Brand 5 & 775 & 2 \\
Brand 6 & 222 & 912 \\
Brand 7 & 213 & 261 \\
\hline
\end{tabular}

Table $1 b$

Concentrations of casein and total milk protein in dark chocolate sprinkles with a precautionary labelling for milk allergens

\begin{tabular}{|l|l|l|}
\hline $\begin{array}{l}\text { Dark chocolate sprinkles } \\
\text { - labeled for milk allergens - }\end{array}$ & $\begin{array}{l}\text { Casein concentration } \\
(\mathrm{mg} / \mathrm{kg})\end{array}$ & $\begin{array}{l}\text { Total milk protein } \\
\text { concentration* } \\
(\mathrm{mg} / \mathrm{kg})\end{array}$ \\
\hline Brand 8 & 3 & 4 \\
Brand 9 (production code a) & 88 & 104 \\
Brand 9 (production code b) & 156 & 184 \\
\hline
\end{tabular}

Table 1c

Concentrations of casein and total milk protein in milk chocolate sprinkles

\begin{tabular}{|l|l|l|}
\hline Milk chocolate sprinkles & $\begin{array}{l}\text { Casein concentration } \\
(\mathrm{mg} / \mathrm{kg})\end{array}$ & $\begin{array}{l}\text { Total milk protein } \\
\text { concentration* } \\
(\mathrm{mg} / \mathrm{kg})\end{array}$ \\
\hline Brand 9 & 73000 & 85882 \\
Brand 2 & 53000 & 62353 \\
Brand 8 & 63000 & 74118 \\
\hline
\end{tabular}

* $\quad$ calculated from casein concentration (casein concentration x $100 \div 85$ )

** complaint sample

Table 2

Percentages of the milk protein allergic population expected to experience an allergic reaction due to unlabeled dark chocolate sprinkles

\begin{tabular}{|c|c|c|c|c|c|c|c|c|c|}
\hline \multirow{3}{*}{\multicolumn{2}{|c|}{$\begin{array}{l}\text { Concentration of } \\
\text { the milk protein } \\
\text { contamination } \\
(\mathrm{mg} / \mathrm{kg})\end{array}$}} & \multicolumn{4}{|c|}{$\begin{array}{l}\text { Expected responders among milk allergic } \\
\text { consumers of the product* } \\
(\%)\end{array}$} & \multicolumn{4}{|c|}{$\begin{array}{l}\text { Expected responders within the milk } \\
\text { allergic population } * * \\
(\%)\end{array}$} \\
\hline & & \multicolumn{2}{|c|}{$\begin{array}{l}\text { Subjective allergic } \\
\text { reactions }\end{array}$} & \multicolumn{2}{|c|}{$\begin{array}{l}\text { Objective allergic } \\
\text { reactions }\end{array}$} & \multicolumn{2}{|c|}{$\begin{array}{l}\text { Subjective allergic } \\
\text { reactions }\end{array}$} & \multicolumn{2}{|c|}{$\begin{array}{l}\text { Objective allergic } \\
\text { reactions }\end{array}$} \\
\hline & & $\mathrm{M}$ & $\mathrm{F}$ & $\mathrm{M}$ & $\mathrm{F}$ & $\mathrm{M}$ & $\mathrm{F}$ & $\mathrm{M}$ & $\mathrm{F}$ \\
\hline Brand 1a & 1765 & 57.5 & 50.3 & 7.7 & 5.8 & 7.2 & 5.0 & 1.0 & 0.6 \\
\hline Brand $1 b$ & 100 & 21.6 & 17.1 & 1.1 & 0.8 & 2.7 & 1.7 & 0.1 & 0.1 \\
\hline Brand 1c & 3547 & 67.9 & 61.3 & 12.2 & 9.2 & 8.6 & 6.1 & 1.5 & 0.9 \\
\hline Brand 2a & 540 & 38.7 & 32.9 & 3.5 & 2.6 & 4.9 & 3.3 & 0.4 & 0.3 \\
\hline
\end{tabular}


Risk Undeclared Allergens

\begin{tabular}{|l|l|l|l|l|l|l|l|l|l|}
\hline Brand 2b & 1845 & 58.2 & 51.0 & 8.0 & 6.0 & 7.2 & 5.1 & 1.0 & 0.6 \\
\hline Brand 3 & 18 & 8.9 & 6.3 & 0.3 & 0.3 & 1.1 & 0.7 & 0 & 0 \\
\hline Brand 4 & 2 & 2.3 & 1.9 & 0.1 & 0 & 0.3 & 0.2 & 0 & 0 \\
\hline Brand 5 & 912 & 46.9 & 39.8 & 5.0 & 3.7 & 5.9 & 4.0 & 0.6 & 0.4 \\
\hline Brand 6 & 261 & 30.9 & 26.5 & 2.1 & 1.6 & 3.9 & 2.7 & 0.3 & 0.2 \\
\hline
\end{tabular}

* non-users of dark chocolate sprinkles excluded

** non-users of dark chocolate sprinkles included 


\section{Risk Undeclared Allergens}

Figure 1 Percentages of predicted responders in the milk allergic population to the different contaminated samples

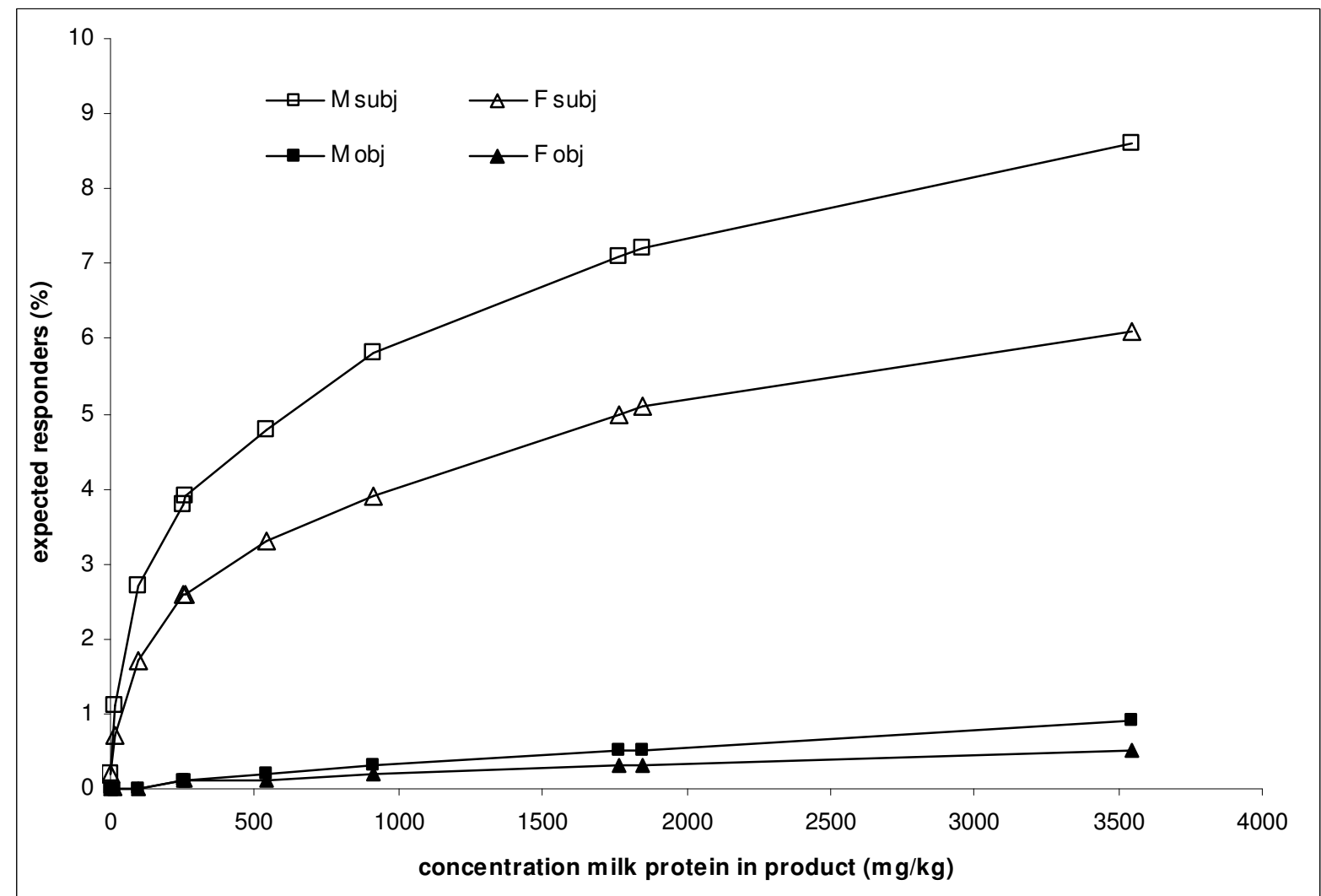

$\mathrm{M} / \mathrm{F}$, males/females; Based on the concentrations of ten samples of dark chocolate sprinkles from packagings not labeled as 'may contain milk protein' and the average consumption levels of this product; Calculated using the software programme @-RISK (version 3.5.2), 25 runs of 10000 iterations for each simulation; Cumulative distributions for consumption and concentration data; Cumulative, LogLogistic, LogNormal or Weibull distributions for subjective symptoms (results of the fitted distribution that gave the highest risk shown); LogLogistic, LogNormal or Weibull distributions for objective symptoms (results of the fitted distribution that gave the highest risk shown); The outcome $p$ (the chance on an allergic reaction) is the success probability for a Bernoulli distribution; Pooled standard deviations were too low to have impact on the outcome. 